\title{
Skull base repair following endonasal pituitary and skull base tumour resection: a systematic review
}

\author{
Danyal Z. Khan ${ }^{1,2}$ (D) Ahmad M. S. Ali ${ }^{3} \cdot$ Chan Hee Koh $^{1,2} \cdot$ Neil L. Dorward $^{1} \cdot$ Joan Grieve' ${ }^{1}$ Hugo Layard Horsfall ${ }^{1,2}$. \\ William Muirhead $^{1,2}$. Thomas Santarius ${ }^{4}$. Wouter R. Van Furth ${ }^{5}$. Amir H. Zamanipoor Najafabadi ${ }^{5}$. Hani J. Marcus ${ }^{1,2}$
}

Accepted: 26 March 2021 / Published online: 10 May 2021

(C) The Author(s) 2021

\begin{abstract}
Purpose Postoperative cerebrospinal fluid rhinorrhoea (CSFR) remains a frequent complication of endonasal approaches to pituitary and skull base tumours. Watertight skull base reconstruction is important in preventing CSFR. We sought to systematically review the current literature of available skull base repair techniques.

Methods Pubmed and Embase databases were searched for studies (2000-2020) that (a) reported on the endonasal resection of pituitary and skull base tumours, (b) focussed on skull base repair techniques and/or postoperative CSFR risk factors, and (c) included CSFR data. Roles, advantages and disadvantages of each repair method were detailed. Random-effects metaanalyses were performed where possible.

Results 193 studies were included. Repair methods were categorised based on function and anatomical level. There was absolute heterogeneity in repair methods used, with no independent studies sharing the same repair protocol. Techniques most commonly used for low CSFR risk cases were fat grafts, fascia lata grafts and synthetic grafts. For cases with higher CSFR risk, multilayer regimes were utilized with vascularized flaps, gasket sealing and lumbar drains. Lumbar drain use for high CSFR risk cases was supported by a randomised study (Oxford CEBM: Grade B recommendation), but otherwise there was limited high-level evidence. Pooled CSFR incidence by approach was 3.7\% (CI 3-4.5\%) for transsphenoidal, 9\% (CI 7.2-11.3\%) for expanded endonasal, and 5.3\% (CI 3.4-7\%) for studies describing both. Further meaningful meta-analyses of repair methods were not performed due to significant repair protocol heterogeneity.

Conclusions Modern reconstructive protocols are heterogeneous and there is limited evidence to suggest the optimal repair technique after pituitary and skull base tumour resection. Further studies are needed to guide practice.
\end{abstract}

Keywords Endoscopic transsphenoidal surgery $\cdot$ Endoscopic endonasal $\cdot$ Skull base surgery $\cdot$ Cerebrospinal fluid $\cdot$ CSF . Cerebrospinal fluid leak $\cdot$ Cerebrospinal fluid rhinorrhoea

Danyal Z. Khan and Ahmad M. S. Ali have been equally contributed as first authors.

Hani J. Marcus

h.marcus@ucl.ac.uk

1 Division of Neurosurgery, National Hospital for Neurology and Neurosurgery, Queen Square, London, UK

2 Wellcome/EPSRC Centre for Interventional and Surgical Sciences, University College London, London, UK

3 Department of Neurosurgery, The Walton Centre, Liverpool, UK

4 Division of Neurosurgery, University of Cambridge and Cambridge University Hospitals, Cambridge, UK

5 Department of Neurosurgery, University Neurosurgical Centre Holland, Leiden University Medical Centre, Haaglanden Medical Centre and Haga Teaching Hospital, Leiden and The Hague, The Netherlands

\author{
Abbreviations \\ CSF Cerebrospinal fluid \\ ioCSFL Intraoperative cerebrospinal fluid leak \\ CSFR Cerebrospinal fluid rhinorrhoea \\ TSA Transsphenoidal approach \\ EEA Endonasal endoscopic approach
}

\section{Background}

Endonasal approaches to the skull base, most commonly described in the transsphenoidal approach (TSA) to pituitary lesions, have allowed minimally invasive and maximally effective surgical resection of skull base tumours. They may allow early optic decompression whilst avoiding excessive vascular manipulation, resulting in superior visual outcomes 
compared to transcranial approaches [1-3]. As these techniques have developed, access to the skull base has been bolstered, establishing the expanded endoscopic endonasal approaches (EEA) - allowing resection of larger pituitary lesions and an increasing variety of skull base tumours beyond the sella alone $[4,5]$.

Despite the purported advantages of endonasal approaches (TSA and EEA), postoperative cerebrospinal fluid rhinorrhoea (CSFR) remains a frequent complication, which may result in significant complications, including meningitis, pneumocephalus and the need for reoperation [6-8]. Reported CSFR rates are variable in the literaturegenerally up to $5 \%$ for TSA and up to $20 \%$ for EEA [7, 9 , 10].

CSFR results from iatrogenic disruption of the barrier between the CSF-containing subarachnoid space and the sinonasal cavity during surgery. This disruption may be unavoidable (e.g. intradural tumour resection) or inadvertent (e.g. most pituitary adenoma resections). Regardless of the cause, a watertight repair of the skull base is paramount in preventing postoperative CSFR [11]. This is a technically challenging task-using long rigid instruments to repair a defect against gravity and under dependent intracranial structures [12]. There are various available repair options with varying morbidity profiles, including reconstructive materials (e.g. fat grafts, nasoseptal flaps) and supportive measures (e.g. lumbar drains) $[11,13]$. These repair choices may be influenced by numerous factors, including approach (TSA or EEA), presence or grade of intraoperative CSF leak (ioCSFL) [14], patient characteristics (e.g. elevated BMI) and surgeon experience $[11,15,16]$. However, there is a paucity of high-quality evidence or consensus on skull base repair methodology, and surgical practice is resultantly heterogenous $[11,13,16]$.

The first step in establishing optimal skull base repair techniques after endonasal resection of pituitary and skull base tumours is understanding the current scope of techniques available. Although there are several studies that review this topic, none are both systematic and comprehensive [11, 17-23]. We therefore sought to systematically review the current literature and produce a framework of available skull base repair techniques, their potential roles, advantages and disadvantages.

\section{Methods}

\section{Search strategy}

This review was conducted in accordance with the Preferred Reporting Items for Systematic Reviews and Meta-Analyses (PRISMA) Statement [24] with the study protocol published a priori in an open-access database
(PROSPERO ID: 42020172372). A search strategy was created using the keywords "transsphenoidal", "endonasal", "EEA", "skull base", "cerebrospinal fluid" and synonyms (Supplementary information 1). Studies from 2000 to 2020 were included if they: (a) reported on resection of pituitary and skull base tumours via TSA/ EEA, (b) focussed primarily on skull base repair techniques and/or postoperative CSFR risk factors, and (c) included the incidence of postoperative CSF rhinorrhoea. Exclusion criteria were: spontaneous/traumatic CSF rhinorrhoea, paediatrics ( $<16$ years old), case series $<3$ patients, editorials, secondary research, animal studies and cadaveric studies. Studies without a specific focus on skull base repair or postoperative rhinorrhoea risk factors were excluded. Both PubMed and Embase databases were searched on 19/06/2020. Duplicates were removed using Endnote X9. Independent abstract screening was performed in duplicate by two authors (DZK, AMSA). Related-article search was performed for each included article. Review of full-text articles ensued, according to the inclusion/exclusion criteria. Any discrepancies in selection were resolved by discussion and mutual agreement.

\section{Data extraction}

Data points extracted from the included articles comprised of: study details (continent, design), tumour characteristics (sample size, tumour type), operative characteristics (surgical approach, intraoperative CSF leak and grade [14], skull base repair materials used and rationale behind choice; CSF diversion use), complications (CSFR incidence/method of confirmation/number requiring reoperation; repair-related complications).

\section{Quality assessment}

A bespoke risk of bias tool (based on COSMOS-E guidelines) [25] was created for study-level assessment focusing on information bias and selection bias (Supplementary information 2). This tool sought to interrogate key study characteristics included sample, ioCSFL, skull base repair and postoperative CSFR. Each study was scored out of 5, stratifying studies into low (score 0-1), moderate (score 2-3) and high (score 4-5) risk of bias. This was a deviation from our protocol, after use of generic assessment tools was felt not to clearly delineate study quality. Additionally, after categorisation of repair methods, each category was assigned a grade of recommendation based on the 2009 Oxford Levels of Evidence Criteria [26]. 


\section{Data analysis}

Repair techniques were organised into a comprehensive taxonomy according to uniting characteristics (e.g. intended function, anatomical level, material type) $[27,28]$. Each category was explored in turn in terms of sub-categories, indications, advantages, disadvantages and refinements. Summary statistics (using Excel, Version 16.43, Microsoft) were generated for the number of studies and cases by pathology, approach, and repair technique. Random-effects meta-analyses (using R “metafor" package, version 3.6.1, R Foundation, Austria) were also performed for the CSFR rates by approach and repair technique where possible. Study heterogeneity was assessed by calculating $\mathrm{I}^{2}$ values $\left(\mathrm{I}^{2}>50 \%\right.$ considered significant).

\section{Results}

\section{General}

The search returned 1165 records (1161 after removal of duplicates). After abstract screening, 256 full-text studies were reviewed with 193 studies included for final analysis (Fig. 1). The yearly rate of publication in this field has been increasing over time (Supplementary information 3). Most studies originated from groups in North America (44.6\%,
86/193), Asia (32.6\%, 63/193) and Europe (18.1\%, 35/193). The majority (191/193) of studies were case series (prospective or retrospective) and 2/193 were randomised controlled trials (RCT). The median risk of bias score of 2 (IQR 1-3) suggestive of moderate risk of bias (Supplementary information 2). Of the included studies, the reported approaches were: TSA $(49.2 \%, 95 / 193)$, EEA $(28.5 \%, 55 / 193)$, or both $(22.3 \%, 43 / 193)$. The most frequent pathologies are highlighted in Table 1-reported at study level only as many studies did not report frequency for each pathology included.

\section{Repair techniques}

Numerous materials and techniques were reported within the included studies. There was almost absolute heterogeneity, with no studies (from different author groups) sharing the same repair protocol (Supplementary information 4).

The choice of the number of layers and the type of repair was often decided based on pre- or intra-operative considerations. A predominant consideration was the presence and severity of ioCSFL [14, 29-34], with the Esposito-Kelly grading system serving as a basis for many repair protocols [14]. Patient-related factors considered in planning repair strategy included age (e.g. poor wound healing in the elderly), elevated body mass index, previous endonasal surgery and concomitant radiotherapy [10, 28, 35-41]. Tumour-related factors included pathology type
Fig. 1 PRISMA flow chart of paper identification, screening and eventual inclusion
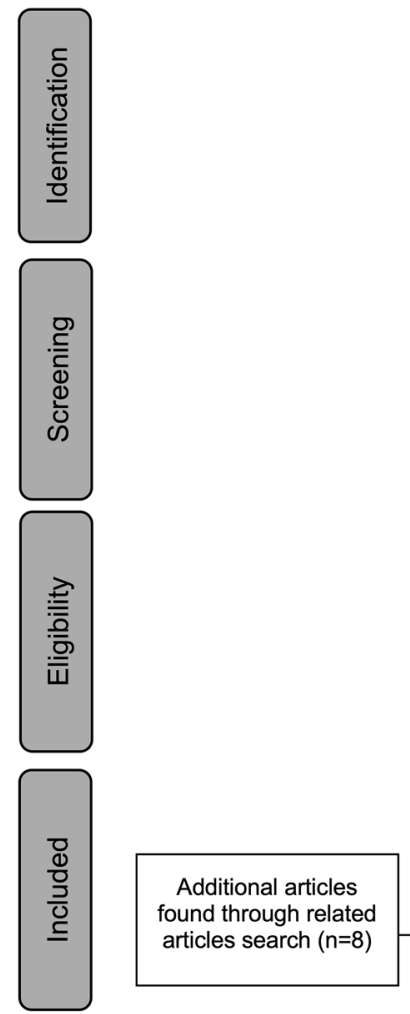

Additional records identified through Medline \& EMBASE on $19 / 06 / 20(n=1165)$
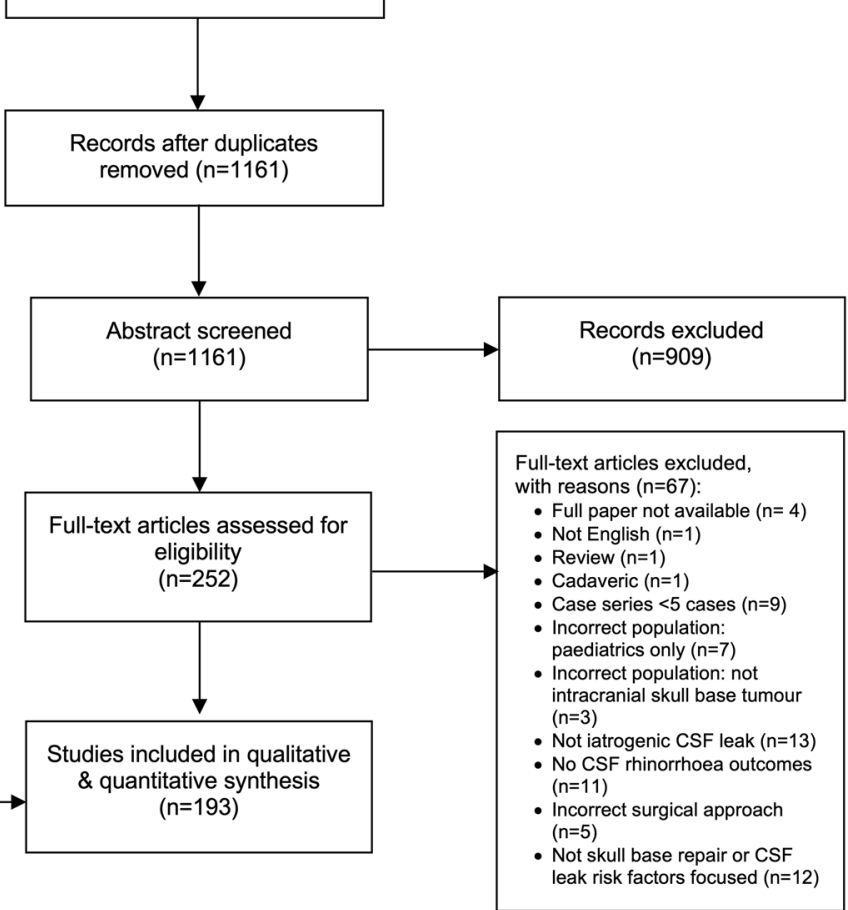
Table 1 Commonest pathologies treated using the transsphenoidal or expanded endonasal approach

\begin{tabular}{|c|c|}
\hline Most common pathology types & No. of studies \\
\hline Pituitary adenoma & 156 \\
\hline Rathke Cleft Cyst & 65 \\
\hline Craniopharyngioma & 92 \\
\hline Chordoma & 56 \\
\hline Meningioma (e.g. planum sphenoidale, tuberculum sellae, clival, cavernous, olfactory groove) & 77 \\
\hline Arachnoid cyst & 14 \\
\hline Metastatic (e.g. breast, renal, melanoma) & 17 \\
\hline Other cysts (epidermoid, dermoid, colloid, hydatid) & 14 \\
\hline Other pathologies included & Examples \\
\hline Central nervous tissue & $\begin{array}{l}\text { Esthesioneuroblastoma } \\
\text { Pituicytoma } \\
\text { Pituitary apoplexy } \\
\text { Schwannoma } \\
\text { Optic glioma } \\
\text { Pilocytic astrocytoma } \\
\text { Hypothalamic hamartoma }\end{array}$ \\
\hline Connective tissue & $\begin{array}{l}\text { Chondrosarcoma } \\
\text { Osteosarcoma } \\
\text { Sarcoma }\end{array}$ \\
\hline Vascular & $\begin{array}{l}\text { Hemangioblastoma } \\
\text { Cavernoma }\end{array}$ \\
\hline Haematological & $\begin{array}{l}\text { Lymphoma } \\
\text { Plasmacytoma }\end{array}$ \\
\hline Miscellaneous & $\begin{array}{l}\text { Germinoma } \\
\text { Glomus jugulare } \\
\text { Granular cell tumour } \\
\text { Xanthogranuloma } \\
\text { Mucocele } \\
\text { Papilloma } \\
\text { Cystic adenocarcinoma }\end{array}$ \\
\hline
\end{tabular}

[28, 31, 33, 35, 42, 43], size, extension (e.g. suprasellar extension) [31] and consistency [43]. Operative factors consisted of the presence of intrasellar dead space [14, 44], dural morphology (thinned or tense) [31, 45] and osteodural defect size $[33,46,47]$. When considering osteodural defect location, transplanum (where the exposed optic chiasm cannot provide counter pressure to support the repair) and clival (vertical plane and are often large/ high flow) defects were considered particularly high risk and required robust repair [28, 37, 46-49].

Below, we discuss these techniques in turn according to our taxonomy (Figs. 2, 3). Table 2 discusses the purposes, advantages and disadvantages at each anatomical phase. The incidences of each of these repair materials across TSA and EEA papers are highlighted in Supplementary Information 5.

\section{Barrier restoring: intradural phase (dural inlay)}

Materials used were autologous or synthetic (Figs. 2, 3). The most common autologous graft was composed of fat (Table 2) from the abdomen or thigh (137 studies) [50-57]. Techniques to mitigate the potential disadvantages (Table 3) of this material included robust dural repair underlying the fat graft with clips [51] or sutures to protect neurovascular structures from overpacking [58]. Dislodgement can be prevented by supporting the graft with a rigid buttress or suturing the graft to the dura ("bath-plug technique") [32, 51]. Premature absorption can be prevented by placing a barrier graft between fat tissue and overlying vascularised flaps [52], whilst harvesting the fat via an intra-umbilical approach may reduce donor site scarring and morbidity [55]. Additionally, wrapping the fat tissue in barrier grafts (e.g. 


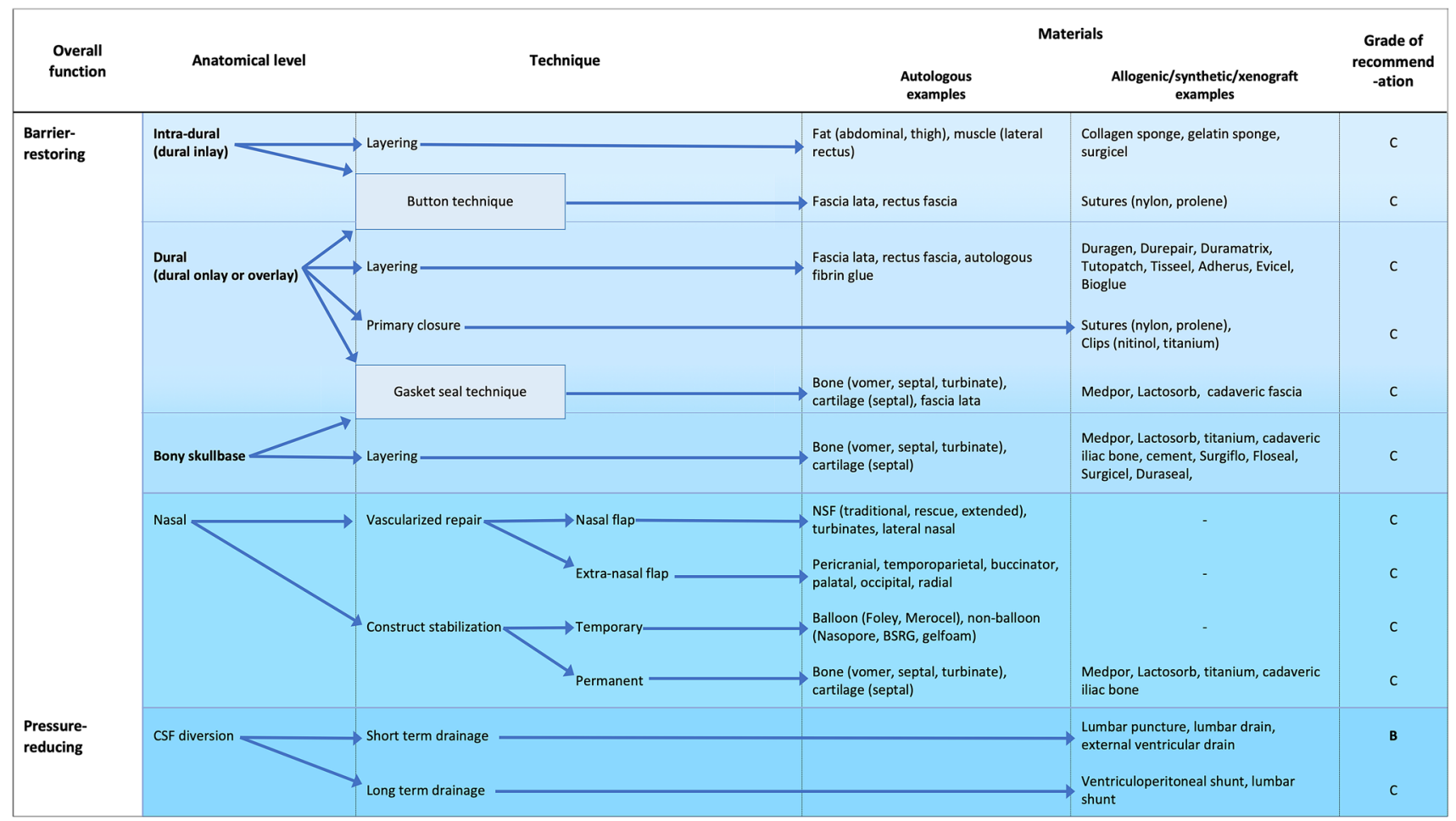

Fig. 2 Repair technique taxonomy

Fig. 3 Sagittal section to the skull base highlighting various levels of repair and common repair techniques used per level

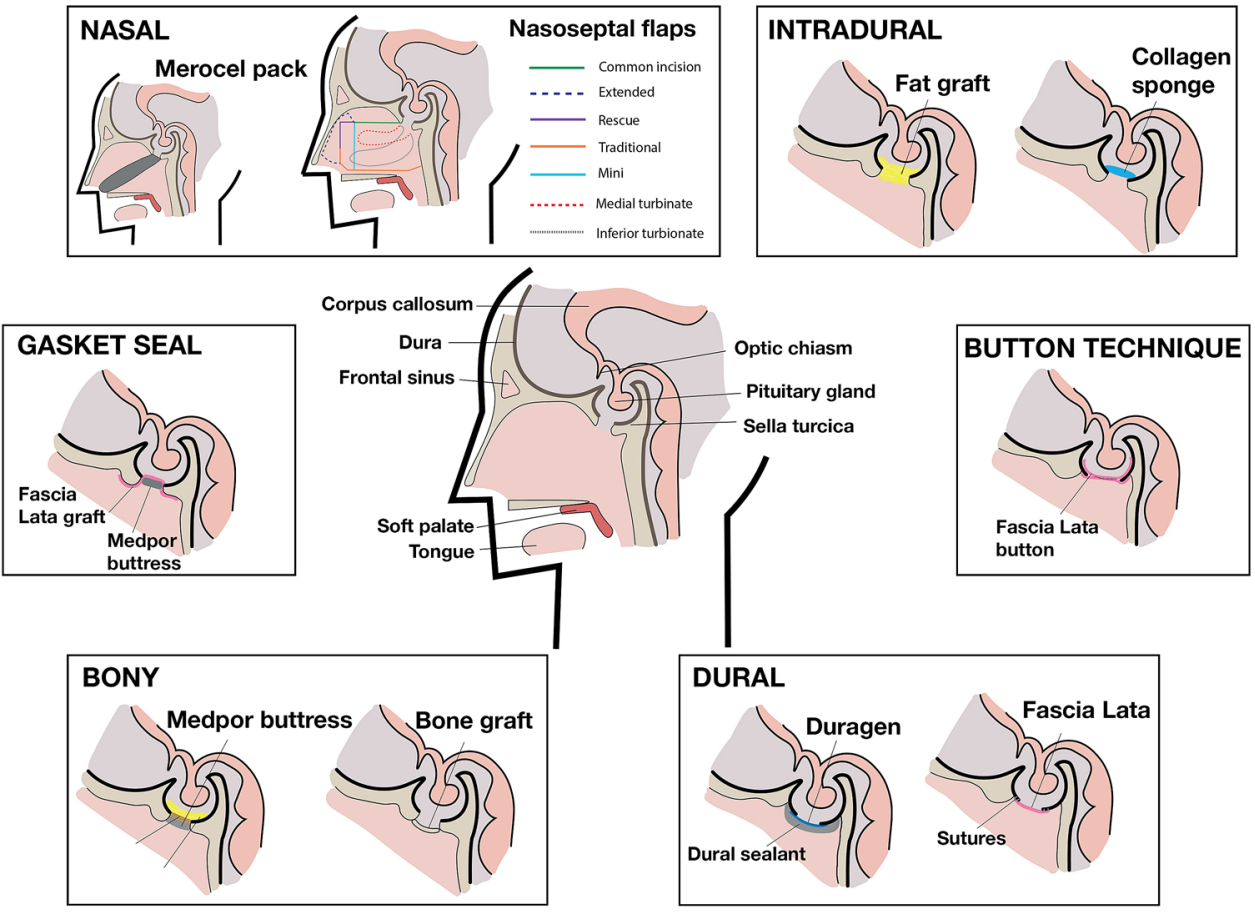

Avitene or oxidised cellulose) may aid placement and stability (prevents lobules detaching) [56, 59]. Alternatively, synthetic grafts can be used for the intra-dural phase-either layered thin grafts (e.g. Alloderm, Tachosil) or sponge-like voluminous grafts (collagen sponges, gelatin sponges) [15, 60-62]. Several studies have found similar CSFR results between synthetic and fat sellar packing packing [60, 62, 63], although some authors suggested fat graft packing was 


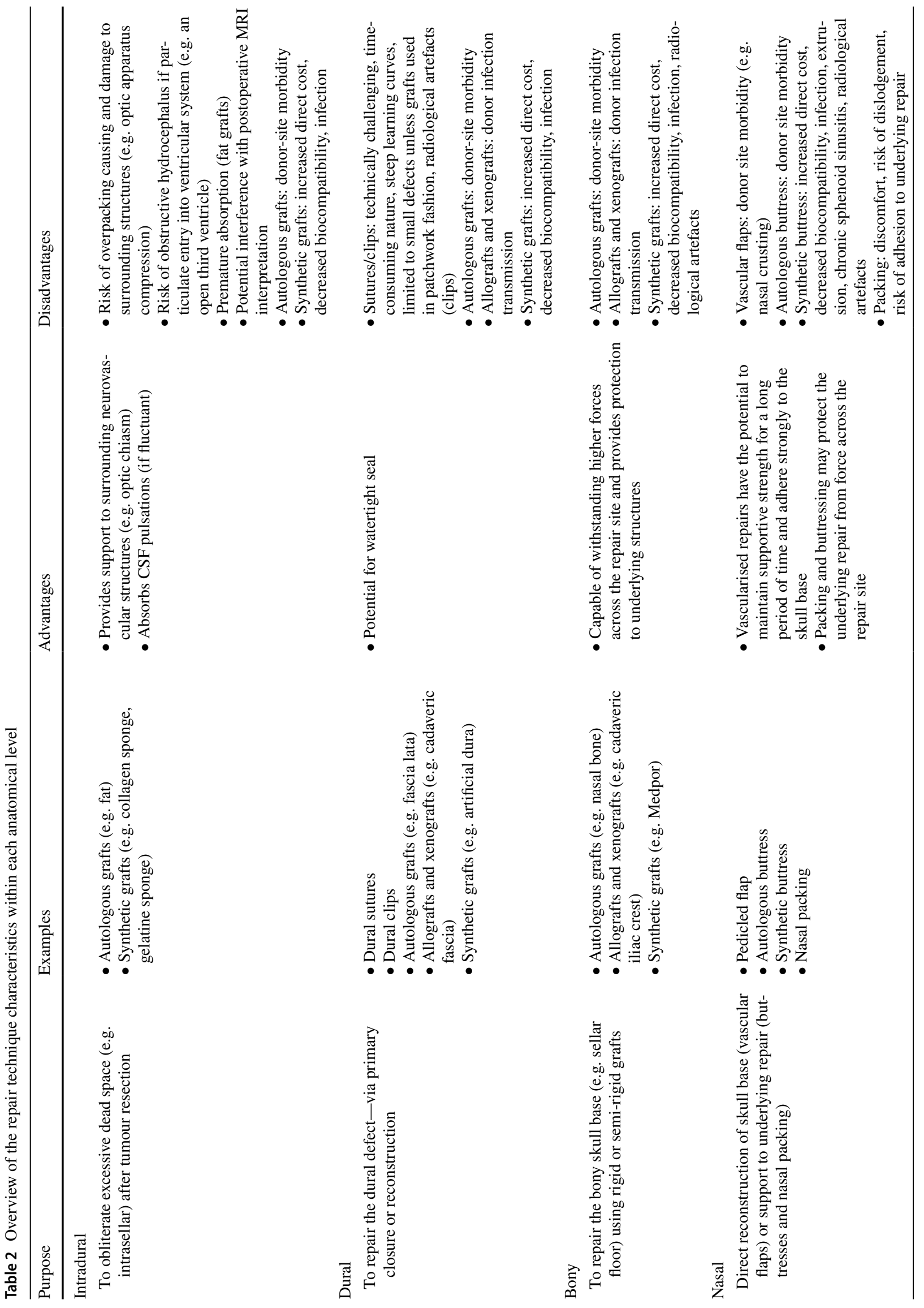


more effective in the context of moderate/large flow ioCSFL [15].

\section{Barrier restoring: dural (dural onlay and overlay)}

Direct closure using suturing (Figs. 2, 3) was reported in 69 papers $[58,64]$. A variety of suture materials were used (e.g. 7-0 pronova [65], 5-0 nylon [66], 5-0 PDS [58]) in a simple or continuous fashion. Some authors preferred continuous suturing (particularly for high flow ioCSFL and large dural defects) due to even tension distribution, the potential for a tighter seal across the defect, and the requirement of only two knots $[42,67]$. To offset some of the challenges of this technique (Table 2) [42, 64, 65, 67-69], surgeons describe suturing grafts (fat, fascia, gelatin sponge) directly to the dura in a patchwork configuration for larger defects $[38,58$, 64-70, 143]. By using specialised suture-tying instruments with a sliding-lock-knot technique, suturing was increasingly feasible $[58,65,66,68]$. Other modifications include the "snare technique": catching redundant dura around an identified leaking point with a loop of suture-sealing the leak without additional puncturing [71]. Similarly, direct dural closure utilising clips (with or without graft patches) is non-penetrating, quicker and less technically demanding than suturing [52, 72-75]. Using particular materials (e.g. Nitinol $[52,75])$ created less radiological artefact than traditional titanium clips [72-74].

Alternatively, dural reconstruction through the use of grafts alone was described in 64 papers. These can be autografts (e.g. fascia lata, septal mucosa), synthetic (e.g. Duramatrix, Duragen), allografts (e.g. cadaveric fascia) or xenografts (e.g. equine pericardium) [41, 76-78]. Autologous options are generally cheaper, universally available and maximally biocompatible $[29,78,79]$. Fascia lata grafts represent an established, strong, versatile and pliable autologous material which is easy to harvest $[44,78]$. Alternatives include nasal mucosa grafts (e.g. septal or turbinate) [80-83] and leukocyte-enriched platelet-rich fibrin membranes harvested from 10 to $20 \mathrm{ml}$ of the patient's bloodboth of which avoid a separate abdominal or thigh incision [84-86]. Similarly, autologous dura may be used to reconstruct defects by forming a dural flap at the time of durotomy which is subsequently replaced during reconstruction [87]. In terms of synthetic grafts, many are collagen-based and sheet-like (e.g. Duragen), with some fibrinogen-coated (e.g. Tachosil or Tachocomb) to increase adhesion [41, 76, 88]. Other options included collagen sponges (e.g. Spongostan, Tissuefleece), gelatin sponges (Gelfoam), oxidised cellulose (Surgicel) [29, 79, 89], and nanofibrous scaffolds (e.g. ReDura) which may reduce graft infection through the promotion of native dura ingrowth [78]. Moreover, allografts, like synthetic materials, avoid the donor-related complications of autografts. For example, acellular dermis 
Table 3 The rates and methods of confirmation and management of intraoperative CSF leak and postoperative CSF rhinorrhoea

\begin{tabular}{|c|c|c|c|}
\hline Measure & Transsphenoidal approach & Expanded endonasal approach & Both approaches \\
\hline \multicolumn{4}{|l|}{ Intraoperative CSF leak } \\
\hline No. of studies reporting & $87 / 95(92 \%)$ & $53 / 55(97 \%)$ & $32 / 43(82 \%)$ \\
\hline $\begin{array}{l}\text { Methods of confirmation (number of } \\
\text { studies) }\end{array}$ & $\begin{array}{l}\text { Valsalva }(n=32) \\
\text { IT fluorescein }(n=6) \\
\text { Observation alone }(n=2) \\
\text { IT saline }(n=1) \\
\text { Not specified }(n=54)\end{array}$ & $\begin{array}{l}\text { Valsalva }(n=3) \\
\text { IT fluorescein }(n=5) \\
\text { Observation alone }(n=2) \\
\text { Not specified }(n=45)\end{array}$ & $\begin{array}{l}\text { Valsalva }(n=12) \\
\text { IT fluorescein }(n=4) \\
\text { Observation alone }(n=2) \\
\text { Not specified }(n=25)\end{array}$ \\
\hline Grading methods (number of studies) & $\begin{array}{l}\text { Esposito-Kelly }(n=15) \\
\text { High/low flow }(n=13) \\
\text { Modified Esposito-Kelly }(n=1) \\
\text { Anatomical grading }(n=2) \\
\text { Not specified }(n=64)\end{array}$ & $\begin{array}{l}\text { Esposito-Kelly }(n=4) \\
\text { High/low flow }(n=12) \\
\text { Not specified }(n=43)\end{array}$ & $\begin{array}{l}\text { Esposito-Kelly }(n=13) \\
\text { High/low flow }(n=12) \\
\text { Modified Esposito-Kelly }(n=2) \\
\text { Not specified }(n=16)\end{array}$ \\
\hline \multicolumn{4}{|l|}{ Postoperative CSF rhinorrhea } \\
\hline No. of studies reporting & $94 / 95(99 \%)$ & $55 / 55(100 \%)$ & $41 / 43(95 \%)$ \\
\hline $\begin{array}{l}\text { Adjuncts for confirmation (number of } \\
\text { studies) }\end{array}$ & $\begin{array}{l}\beta 2 \text { transferrin }(n=10) \\
\text { tes-tape }(n=1) \\
\text { Not specified }(n=84)\end{array}$ & $\begin{array}{l}\text { Pneumocephalus on CT }(n=2) \\
\beta 2 \text { transferrin }(n=3) \\
\text { Not specified }(n=50)\end{array}$ & $\begin{array}{l}\beta 2 \text { transferrin }(n=4) \\
\text { Pneumocephalus on CT }(n=5) \\
\text { MRI }(n=3) \\
\text { Leaning forward }(n=4) \\
\text { Tch99 cisternography }(n=1) \\
\text { IT fluorescein }(n=1) \\
\text { Endoscopic exploration }(n=2) \\
\text { Not specified }(n=23\end{array}$ \\
\hline $\begin{array}{l}\text { CSFR management methods (number of } \\
\text { studies) }\end{array}$ & $\begin{array}{l}\text { Lumbar drain }(n=28) \\
\text { Reoperation }(n=46) \\
\text { VPS }(n=2) \\
\text { Combined lumbar drain and } \\
\text { reoperation }(n=17) \\
\text { Serial lumbar punctures }(n=1) \\
\text { Not specified }(n=1)\end{array}$ & $\begin{array}{l}\text { Lumbar drain }(n=18) \\
\text { Reoperation }(n=30) \\
\text { VPS }(n=3) \\
\text { EVD }(n=1) \\
\text { Not specified }(n=3)\end{array}$ & $\begin{array}{l}\text { Lumbar drain }(n=15) \\
\text { Reoperation }(n=24) \\
\text { Combined lumbar drain and } \\
\text { reoperation }(n=4) \\
\text { Not specified }(n=8)\end{array}$ \\
\hline
\end{tabular}

$I T$ intrathecal, $T c h$ technetium, $C S F$ cerebrospinal fluid, $M R I$ magnetic resonance imaging, $C T$ computed topography, VPS ventriculo-peritoneal shunt, $E V D$ external ventricualr drain

or dehydrated amniotic membrane, both of which are biocompatible and encourage native tissue growth [90-92]. Xenografts, such as equine pericardium sheet or equine collagen foil, retain many of these benefits, with some products having a lower infectious transmission profile (e.g. no bovine spongiform encephalopathy risk with equine products) $[77$, 93].

Finally, dural reconstruction with grafts may be augmented by employing the button technique [94]. This involved suturing a larger barrier graft (e.g. fascia lata) to a smaller barrier graft in a stacked fashion. This construct was manoeuvred so that the larger graft underlays the defect (intradural phase) whilst the small defect lies as an overlay (dural phase), producing a watertight plug. This technique may decrease CSFR rates in the context of high flow ioCSFL in EEA (decreasing CSFR rates from 45 to $10 \%, \mathrm{p}=0.03$ ) in this subgroup [94].

Tissue glues and haemostatic agents can be used to consolidate the dural phase and are described across almost all phases of repair. In included studies, tissue glues were used to stabilise the repair construct, create a watertight sealant and/or fill dead space $[4,75,95,96]$. The majority were fibrin-based glues (e.g. Evicel, Tisseel, autologous), but others included polyethylene glycol (e.g. Duraseal), hydrogel (Adherus) and cyanoacrylate (e.g. Bioglue, Cyanoacrylate) based agents. Fibrin-glues offer strong adhesion and are animal- or human-derived, and therefore may carry the risk of allergic response or infection [97, 98]. Some authors highlight the potential for autologous fibrin glue from serum (e.g. Vivostat), which is cost-effective and avoids the risk of immune reaction or infectious transmission $[98,99]$ but may not be feasible if the patient is unable to give this blood (e.g. anaemia). Autologous glues tend to be less viscous and have a slightly slower coagulation time than synthetic alternatives [99]. Polyethylene glycol and cyanoacrylate glues are entirely synthetic, solidify in seconds with strong adhesion $[39,100]$. Taken together, equipoise remains about the optimal tissue glue $[100,101]$. Moreover, haemostatic materials can be divided into those which are liquid at application and those solid at application. Liquid agents included Surgiflo and Floseal whilst solid agents included Surgicel and Avitene. 
Like tissue glues, they can be used in isolation or as part of multilayer graded regimes [30, 69, 102-104].

\section{Barrier restoring: bony skull base}

Rigid or semi-rigid materials used can be autografts, allografts, xenografts or synthetic (Table 2, Figs. 2, 3). Autologous options include cartilage (e.g. septal) and bone (e.g. vomer) grafts [105]. Some authors describe a skull base craniotomy (crafting and eventually replacing a bone flap from the sellar floor) instead of traditional craniectomy, repairing the bony integrity and providing a foundation for nasoseptal flap adhesion [105]. Allograft alternatives include cadaveric radiation-sterilized iliac bone [106]. Other approaches include the use of mouldable cement (hydroxyapatite or polymethylmethacrylate) $[29,70,79,89,107,108]$.

The bony phase may be augmented by the use of the gasket seal technique, in which a sheet-like graft (e.g. fascia lata) is placed as an oversized overlay to a bony skull base defect and a rigid graft (e.g. polyethylene, titanium, bone) is countersunk into the defect to create a watertight seal [109]. This technique was used in 20 papers, particularly in the context of large and high-flow defects, and is cited as an option that could potentially spare the need for vascularised repair, lumbar drainage and nasal packing [109-111]. However, it requires a suitable bony rim and may not be possible in multiplanar defects [110, 112]. A modified version, the "one-piece gasket-seal" used a unitized (via sutures) Medpor and fascia construct, reducing the technical demand of placement, decreasing the time required of manoeuvring the two components into position intra-nasally, and avoiding the need for an underlying fat graft to provide counterpressure during countersinking of the rigid buttress [57].

\section{Barrier restoring: nasal}

Pedicled vascular flaps (Supplementary information 6) have been a critical advancement in skull base repair methodsused in 169 of included papers (Figs. 2, 3). They can be harvested from nasal (e.g. nasoseptal flaps) or extra-nasal (e.g. pericranial) regions. Their use is particularly described in high flow ioCSFL with large skull base defects, as part of graded multilayer repair protocols [34, 37, 52, 75, 113-119].

The sentinel pedicled vascular flap technique, the nasoseptal flap (NSF), was described by Hadad-Bassagasteguy in 2006. It boasts a rich vascular pedicle (based on the posterior nasoseptal arteries), making it robust and versatile. The NSF was the first-line for vascularised repairs of anterior, middle, clival, sellar and lateral/parasellar defects across many protocols $[31,37,75,113,120]$. It is technically easy to raise, although there is a learning curve associated with its effective use $[75,121]$. Principle disadvantages of NSF included sinonasal morbidity (e.g. crusting, loss of smell, sinusitis, nasal perforations, adhesions, synechiae) and potential iatrogenic damage to the raised flap/ pedicle intraoperatively [52, 122-124]. Rivera-Serrano et al. described the "rescue" NSF technique, which allows protection of the vascular pedicle early in the operation so that the choice to raise a full NSF or not is available at the reconstruction phase of the operation [125]. Several modifications of this "rescue" technique are described, including the "pedicle sparing-transposition technique" [126], "Sigmoid incision rescue flap" [127], and the "hemi-transeptal" technique [122, 124]. For larger EEA defects, bilateral NSFs have been described (with some authors also advocating for their use in the context of expected radiotherapy) [116, $117,121,126]$, as well as extended unilateral NSFs which incorporate inferior turbinate mucosa and lateral nasal wall mucosa [71]. Finally, NSFs were often used as part of multilayer repair regime, one example of this is the " $3 \mathrm{~F}$ " ("fat, flap, flash") technique used after EEA in which a fat graft fills the dead space ("fat"), stabilised with fibrin glue, then covered by NSF ("flap") which is supported by Merocel packing-allowing fast mobilisation ("flash") [50].

In the absence of the NSF, multiple other nasal and extranasal flaps were described (Supplementary information 6), with their use tailored to defect sizes and location. For anterior defects: middle turbinate flaps, pericranial flaps, buccinator flap, palatal, occipital, radial (free) flaps or vastus lateralis (free) flaps were used [31, 120, 121, 128-133]. For posterior/clival defects, options included the temporoparietal flap and inferior turbinate flaps [31, 120, 132, 134]. Other options included the lateral nasal wall, sellar floor, superior turbinate, "U" inverted rhinopharyngeal and nasopharyngeal (mucosal and muscle) flaps [28, 59, 135, 136].

Whilst vascularised flaps form part of the skull base reconstruction, measures such as buttresses and packing provide external stabilisation (temporary or permanent) to the established construct. Buttressing materials were described in 94 studies and used particularly in the context of ioCSFL. They were autologous (e.g. bone) or synthetic (e.g. Medpor, titanium mesh) [92, 109, 131, 137-140]. Medpor buttresses were commonly used, having the advantage of being mouldable, porous and relatively inert $[57,92,137,139]$. Titanium mesh, although strong and mouldable, is not porous. Therefore, it prevents tissue ingrowth (which improves stabilisation and decreases infection) [139]. Additionally, nasal packing was described in 96 studies, being balloon or non-balloon based. Balloon-based methods included Foley catheters, Merocel sponges and Rapid Rhino balloons [37, 44, 46, 57, 115]. The shape of the balloons may be important for support distribution, stability and patient comfort — with tubular-shaped balloons (e.g. Merocel) being considered more favourable by some authors than spherical (e.g. Foley) counterparts [44]. Non-balloon-based packing (e.g. Nasopore, iodoform gauze, polyvinyl alcohol sponge, 
bismuth soaked ribbon gauze, Gelfoam packing), maybe more comfortable, more mouldable, and thus provided a more even support distribution across the repair [115, 141]. Defect location may inform the choice of packing, for example, Foley catheters for sellar or parasellar support and tampon sponges for cribriform or clival support [37]. Antibiotic impregnation of packing (e.g. gentamicin-soaked Gelfoam, Merocel covered in bacitracin ointment) may reduce colonisation of bacteria on the repair construct and may improve underlying healing $[44,71,142]$.

\section{Pressure reducing: CSF diversion}

CSF diversion can be used for treatment or prevention of CSFR (Figs. 2, 3, Table 2). Temporary diversion measures include lumbar drainage (often placed pre-operatively for high-risk CSFR cases or immediately postoperatively in reaction to ioCSFL), lumbar puncture, or rarely, external ventricular drainage (e.g. if concomitant acute hydrocephalus). Medium- and long-term options include ventriculoperitoneal and lumbar shunts-again, usually in the context of concomitant underlying hydrocephalus. A recent randomised controlled trial by Zwagerman et al. suggested that perioperative lumbar drain (in the context EEA with dural defects $>1 \mathrm{~cm}^{2}$ and high flow ioCSFL) decreased CSFR rates when combined with nasoseptal flap repair [34]. In this study, lumbar drains were inserted immediately postoperatively (under the same general anaesthetic), draining $10 \mathrm{ml} / \mathrm{h}$ for 3 days. $8.2 \%$ of those with lumbar drainage and $21.2 \%$ of those without lumbar drainage had CSFR during follow-up $(p=0.03)$ [34]. Observational studies echo the utility of perioperative (post-procedural) in this high CSFR risk context, in combination with NSF [10, 115, 143]. Additionally, pre-procedural lumbar drainage may facilitate tumour resection (by allowing drainage of CSF or injection of intrathecal saline [49]) and allow the use of other intrathecal adjuncts (e.g. fluorescein) [144, 145]. The evidence in low flow ioCSFL and smaller defects (TSA) is less robust [146] and again, largely observational [34, 147, 148].

\section{Postoperative CSF rhinorrhoea}

The methods of confirming and grading intraoperative CSF leak rates are summarised in Table 3. The pooled incidence of ioCSFL rate (if reported) was $4.6 \%$ (CI $3.7-5.6 \%$, $^{2}$ 98.1\%, Cochran's Q p < 0.01) for TSA, 9.6\% (CI 9.1-9.8\%, $\mathrm{I}^{2} 89.2 \%$, Cochran's Q: $\mathrm{p}<0.01$ ) for EEA and $7.9 \%$ (CI 6.4-8.9\%, I ${ }^{2} 89.2 \%$, Cochran's Q: $\mathrm{p}<0.01$ ) for studies describing both approaches. Additionally, the methods of confirming, grading, and managing postoperative CSFR are summarised in Table 3. The pooled incidence of CSFR rates (if reported) was 3.7\% (CI 3-4.5\%, $\mathrm{I}^{2} 72.8 \%$, Cochran's Q: $\mathrm{p}<0.01$ ) for TSA, $9 \%$ (CI 7.2-11.3\%, $\mathrm{I}^{2} 54.9 \%$, Cochran's Q: $\mathrm{p}<0.01$ ) for EEA and 5.3\% (CI 3.4-7\%, $\mathrm{I}^{2}$ 90.2\%, Cochran's $\mathrm{Q}: \mathrm{p}<0.01)$ for studies describing both. Totally heterogeneous protocols used across the included studies did not allow for meaningful meta-analyses of techniques and materials.

\section{Discussion}

\section{Principle findings}

This systematic review of skull base repair during endonasal pituitary and skull base tumour resection has highlighted the wide scope of repair techniques used, which is increasing yearly in parallel with the increasing indications for endonasal approaches.

Reconstruction of the skull base is challenging - using long rigid instruments in a restricted working space to place repair materials (with varying risk and morbidity profiles) against the forces of gravity and overlying dependent intracranial structures [12]. In the context of these challenges, this article presents a comprehensive taxonomy that highlights the principles of barrier restoration, pressure relief and the use of staged approaches to prevent CSFR (Figs. 2, 3 ). Protocols were totally heterogeneous between author groups-ranging from the use of one material at a single level (intradural, dural, bony, nasal) to a complex multilevel closure. Most protocols employed a graded protocol, tailoring the extent of reconstruction to the risk of postoperative CSF leak. Techniques most commonly used in the absence of ioCSFL or the presence of low-grade ioCSFL included fat grafts (most commonly abdominal), sheet-like grafts (e.g. fascia lata) or synthetic materials (e.g. Surgicel) and non-balloon nasal packs (e.g. Nasopore). On the other hand, in the context of high-grade ioCSFL, studies described multilayer regimes with vascularized flaps, gasket sealing, balloon-based packing and lumbar drain use to prevent CSFR.

To date, there is sparse high-level evidence to recommend most repair methods, except for lumbar drain use in the context of large dural defect size and high flow intraoperative CSF leak (Oxford CEBM: Grade B recommendation) [34]. Pooled CSFR incidence was 3.7\% (CI 3-4.5\%) for TSA, 9\% (CI 7.2-11.3\%) for EEA, and 5.3\% (CI 3.4-7\%) for studies describing both. Totally heterogeneous protocols used across the included studies did not allow for meaningful meta-analyses of techniques and materials.

\section{Findings in the context of other syntheses}

Several reviews (qualitative and quantitative) exploring the available repair techniques in iatrogenic skull base neurosurgery exist. In terms of narrative reviews, Hannan et al. explored methods of skull base repair with historical 
reference and technical details [13]. Reye et al. focused on pedicled and free flaps through narrative discussion, exploring the indications and complication profile for vascularised repair options available [20]. Sughrue and Aghi provided an insight into the challenges posed by pathology in different anatomical regions [19]. Oakley et al. reviewed the literature to produce limited recommendations for various repair categories as well as CSFR management factors not investigated in our review (including the use of perioperative prophylactic antibiotics, postoperative bed rest, CPAP; and the timing of air travel postoperatively) [22].

Where meta-analyses have been attempted to compare repair techniques $[11,17,18]$, strict inclusion criteria have been used to enable specific comparisons. Harvey et al. reviewed 38 studies where the size of the bony/dural defect was reported in order to compare vascularised and non-vascularised autografts in the context of large skull base defects [11]. Postoperative CSFR rates were less in studies using vascular flaps as part of their regime ( $15.6 \%$ vs. $6.7 \%$ with avascular repair) [11]. Soudry et al. explored the effectiveness of multilayer graded regimes in the context of ioCSFL [17]. In the 22 studies included, a meta-analysis suggested that vascularised flaps provided maximal benefit in high flow leak situations reducing CSFR rates from 18 to $6 \%$ with their use (whilst non-vascularised multilayer regimes sufficed for low ioCSFL) [17]. Iavarone et al. commented specifically on the treatment of CSFR (including non-iatrogenic aetiologies), highlighting the introduction of multilayer and vascularised repair in EEA, which may reduce CSFR rates $<5 \%$ [18]. However, these studies acknowledge the limitations of their meta-analyses in light of the repair technique and CSFR reporting heterogeneity in the primary literature $[11$, $17,18]$.

\section{Strengths and limitations}

The principal strength of this review is the systematic and sensitive search strategy, capturing the breadth of surgical practice in this field. By focussing on articles orientated towards repair techniques or CSFR risk factors, a detailed exploration of repair technique roles, categories modifications and disadvantages was synthesised. The taxonomy generated aims to be comprehensive but, owing to the multifunctionality of certain repair materials (e.g. Surgicel), has overlapping techniques within levels. General limitations include the pragmatic exclusion of case series which captured surgeries but with a focus other than skull base repair or CSFR. Of the included studies, there was inconsistent reporting of key data elements (patient demographics, follow-up time, tumour type, tumour size, dural or bony defect, ioCSFL severity), heterogeneity in definitions of CSFR and mixed case populations from which individual data cannot be extracted. This prevented accurate meta-analysis on the comparative CSFR incidence for various repair techniques. We have previously described meta-analyses of CSFR in more defined populations, with analysis on selected repair technique effectiveness [8, 149], however this paper aimed to capture the breadth of repair techniques and material currently in use. A useful future target would be the development of a standardised core data and/or outcome set to allow comprehensive quantitative synthesis of the literature.

\section{Conclusions}

Modern skull base reconstructive protocols are heterogeneous. Most protocols are multi-layered and graded to case-specific risk factors for postoperative CSF rhinorrhoea. This review captures the scope of current repair methods, categorised according to function and anatomical level. Currently, there is limited evidence to guide the optimal repair technique after pituitary and skull base tumour resection. Prospective multicentre studies and registries will be useful in determining current practice and outcomes with a view to generating a consensus, and possibly providing the basis for further randomised studies [150].

Supplementary Information The online version contains supplementary material available at https://doi.org/10.1007/s11102-021-01145-4.

Acknowledgements HJM, DZK, CHK, HLH are supported by the Wellcome/EPSRC Centre for Interventional and Surgical Sciences, University College London. HJM is also funded by the NIHR Biomedical Research Centre at University College London. Figures were produced by Amy Warnock at the Wellcome/EPSRC Centre for Interventional and Surgical Sciences, University College London.

Author contributions All authors contributed to the study conception and design. Material preparation, data collection and analysis were performed by DZK, AMSA, CHK, HLH, AHZN and HJM. The first draft of the manuscript was written by DZK, AMSA and HJM. All authors commented on previous versions of the manuscript. All authors read and approved the final manuscript.

Data availability Available upon reasonable request.

\section{Declarations}

Conflict of interest All authors certify that they have no affiliations with or involvement in any organization or entity with any financial interest (such as honoraria; educational grants; participation in speakers' bureaus; membership, employment, consultancies, stock ownership, or other equity interest; and expert testimony or patent-licensing arrangements), or non-financial interest (such as personal or professional relationships, affiliations, knowledge or beliefs) in the subject matter or materials discussed in this manuscript. 
Ethical approval and informed consent Ethical approval and informed consent were unnecessary due to the nature of the study (study-level systematic review).

Open Access This article is licensed under a Creative Commons Attribution 4.0 International License, which permits use, sharing, adaptation, distribution and reproduction in any medium or format, as long as you give appropriate credit to the original author(s) and the source, provide a link to the Creative Commons licence, and indicate if changes were made. The images or other third party material in this article are included in the article's Creative Commons licence, unless indicated otherwise in a credit line to the material. If material is not included in the article's Creative Commons licence and your intended use is not permitted by statutory regulation or exceeds the permitted use, you will need to obtain permission directly from the copyright holder. To view a copy of this licence, visit http://creativecommons.org/licenses/by/4.0/.

\section{References}

1. Attia M, Kandasamy J, Jakimovski D, Bedrosian J, Alimi M, Lee DLY et al (2012) The importance and timing of optic canal exploration and decompression during endoscopic endonasal resection of tuberculum sella and planum sphenoidale meningiomas. Oper Neurosurg 71(suppl_1):ons58-ons67. https://doi. org/10.1227/NEU.0b013e318258e23d

2. Liu JK, Christiano LD, Patel SK, Tubbs RS, Eloy JA (2011) Surgical nuances for removal of tuberculum sellae meningiomas with optic canal involvement using the endoscopic endonasal extended transsphenoidal transplanum transtuberculum approach. Neurosurg Focus 30(5):E2

3. Muskens IS, Briceno V, Ouwehand TL, Castlen JP, Gormley WB, Aglio LS et al (2018) The endoscopic endonasal approach is not superior to the microscopic transcranial approach for anterior skull base meningiomas: a meta-analysis. Acta Neurochir 160(1):59-75

4. Kassam A, Thomas AJ, Snyderman C, Carrau R, Gardner P, Mintz A et al (2007) Fully endoscopic expanded endonasal approach treating skull base lesions in pediatric patients. J Neurosurg 106(2 Suppl):75-86. https://doi.org/10.3171/ped.2007. 106.2.75

5. Kassam AB, Prevedello DM, Carrau RL, Snyderman CH, Thomas A, Gardner P et al (2011) Endoscopic endonasal skull base surgery: analysis of complications in the authors' initial 800 patients: a review. J Neurosurg 114(6):1544-1568

6. Kono Y, Prevedello DM, Snyderman CH, Gardner PA, Kassam AB, Carrau RL et al (2011) One thousand endoscopic skull base surgical procedures demystifying the infection potential: incidence and description of postoperative meningitis and brain abscesses. Infect Control Hosp Epidemiol 32(1):77-83

7. Ivan C, Ann R, Craig B, Debi P (1997) Complications of transsphenoidal surgery: results of a national survey, review of the literature, and personal experience. Neurosurgery 40(2):225-237

8. Khan DZ, Muskens IS, Mekary RA, Zamanipoor Najafabadi AH, Helmy AE, Reisch R et al (2020) The endoscope-assisted supraorbital "keyhole" approach for anterior skull base meningiomas: an updated meta-analysis. Acta Neurochir. https://doi. org/10.1007/s00701-020-04544-x

9. Dehdashti AR, Ganna A, Witterick I, Gentili F (2009) Expanded endoscopic endonasal approach for anterior cranial base and suprasellar lesions: indications and limitations. Neurosurgery 64(4):677-689

10. Fraser S, Gardner PA, Koutourousiou M, Kubik M, FernandezMiranda JC, Snyderman CH et al (2018) Risk factors associated with postoperative cerebrospinal fluid leak after endoscopic endonasal skull base surgery. J Neurosurg 128(4):1066-1071

11. Harvey RJ, Parmar P, Sacks R, Zanation AM (2012) Endoscopic skull base reconstruction of large dural defects: a systematic review of published evidence. Laryngoscope 122(2):452-459

12. Snyderman CH, Carrau RL, Kassam AB, Zanation A, Prevedello D, Gardner P et al (2008) Endoscopic skull base surgery: principles of endonasal oncological surgery. J Surg Oncol 97(8):658-664

13. Hannan CJ, Kelleher E, Javadpour M (2020) Methods of skull base repair following endoscopic endonasal tumor resection: a review. Front Oncol 10:1614

14. Esposito F, Dusick JR, Fatemi N, Kelly DF (2007) Graded repair of cranial base defects and cerebrospinal fluid leaks in transsphenoidal surgery. Operat Neurosurg 60(suppl_4):ONS-295

15. Kelly DF, Oskouian RJ, Fineman I (2001) Collagen sponge repair of small cerebrospinal fluid leaks obviates tissue grafts and cerebrospinal fluid diversion after pituitary surgery. Neurosurgery 49(4):885-890

16. Komotar RJ, Starke RM, Raper DMS, Anand VK, Schwartz TH (2012) Endoscopic endonasal versus open transcranial resection of anterior midline skull base meningiomas. World Neurosurg 77(5-6):713-724

17. Soudry E, Turner JH, Nayak JV, Hwang PH (2014) Endoscopic reconstruction of surgically created skull base defects: a systematic review. Otolaryngol Head Neck Surg 150(5):730-738

18. Iavarone A, Luparello P, Lazio MS, Comini LV, Martelli F, De Luca O et al (2020) The surgical treatment of cerebrospinal fistula: qualitative and quantitative analysis of indications and results. Head Neck 42(2):344-356. https://doi.org/10.1002/hed. 25981

19. Sughrue ME, Aghi MK (2010) Reconstruction of dural defects of the endonasal skull base. Neurosurg Clin 21(4):637-641

20. Reyes C, Mason E, Solares CA (2014) Panorama of reconstruction of skull base defects: from traditional open to endonasal endoscopic approaches, from free grafts to microvascular flaps. Int Arch Otorhinolaryngol 18:179-186

21. Hannan CJ, Almhanedi H, Al-Mahfoudh R, Bhojak M, Looby S, Javadpour M (2020) Predicting post-operative cerebrospinal fluid (CSF) leak following endoscopic transnasal pituitary and anterior skull base surgery: a multivariate analysis. Acta Neurochir 162(6):1309-1315. https://doi.org/10.1007/s00701-020-04334-5

22. Oakley GM, Orlandi RR, Woodworth BA, Batra PS, Alt JA (2016) Management of cerebrospinal fluid rhinorrhea: an evidence-based review with recommendations. Int Forum Allergy Rhinol 6(1):17-24. https://doi.org/10.1002/alr.21627

23. Snyderman CH, Wang EW, Zenonos GA, Gardner PA (2020) Reconstruction after endoscopic surgery for skull base malignancies. J Neurooncol. https://doi.org/10.1007/s11060-020-03465-0

24. Moher D, Liberati A, Tetzlaff J, Altman DG (2009) Preferred reporting items for systematic reviews and meta-analyses: the PRISMA statement. Ann Intern Med 151(4):264-269

25. Dekkers OM, Vandenbroucke JP, Cevallos M, Renehan AG, Altman DG, Egger M (2019) COSMOS-E: guidance on conducting systematic reviews and meta-analyses of observational studies of etiology. PLoS Med 16(2):e1002742

26. Group OLoEW (2009) The Oxford 2009 levels of evidence. Oxford centre for evidence-based medicine. https://www.cebm. ox.ac.uk/resources/levels-of-evidence/oxford-centre-for-evide nce-based-medicine-levels-of-evidence-march-2009. Accessed 15 Jan 2020

27. Roxbury CR, Saavedra T, Ramanathan M Jr, Lim M, Ishii M, Gallia GL et al (2016) Layered sellar reconstruction with avascular free grafts: acceptable alternative to the nasoseptal flap for repair of low-volume intraoperative cerebrospinal fluid leak. Am J Rhinol Allergy 30(5):367-371 
28. Simal-Julián JA, Miranda-Lloret P, Mena LPdSR, SanrománÁlvarez P, García-Piñero A, Sanchis-Martín R et al (2020) Impact of multilayer vascularized reconstruction after skull base endoscopic endonasal approaches. J Neurol Surg B 81(02):128-135

29. Cappabianca P, Cavallo LM, Valente V, Romano I, D'Enza AI, Esposito F et al (2004) Sellar repair with fibrin sealant and collagen fleece after endoscopic endonasal transsphenoidal surgery. Surg Neurol 62(3):227-233

30. Park J-H, Choi JH, Kim Y-I, Kim SW, Hong Y-K (2015) Modified graded repair of cerebrospinal fluid leaks in endoscopic endonasal transsphenoidal surgery. J Korean Neurosurg Soc 58(1):36

31. Patel MR, Stadler ME, Snyderman CH, Carrau RL, Kassam AB, Germanwala AV et al (2010) How to choose? Endoscopic skull base reconstructive options and limitations. Skull Base 20(6):397

32. Thomas R, Chacko AG (2016) Principles in skull base reconstruction following expanded endoscopic approaches. J Neurol Surg B 77(4):358

33. Ruggeri AG, Cappelletti M, Giovannetti F, Priore P, Pichierri A, Delfini R (2019) Proposal of standardization of closure techniques after endoscopic pituitary and skull base surgery based on postoperative cerebrospinal fluid leak risk classification. $\mathbf{J}$ Craniofac Surg 30(4):1027-1032. https://doi.org/10.1097/scs. 0000000000005540

34. Zwagerman NT, Wang EW, Shin SS, Chang Y-F, FernandezMiranda JC, Snyderman CH et al (2018) Does lumbar drainage reduce postoperative cerebrospinal fluid leak after endoscopic endonasal skull base surgery? A prospective, randomized controlled trial. J Neurosurg 1:1-7

35. Hannan CJ, Almhanedi H, Al-Mahfoudh R, Bhojak M, Looby S, Javadpour M (2020) Predicting post-operative cerebrospinal fluid (CSF) leak following endoscopic transnasal pituitary and anterior skull base surgery: a multivariate analysis. Acta Neurochir. https://doi.org/10.1007/s00701-020-04334-5

36. Nishioka H, Haraoka J, Ikeda Y (2005) Risk factors of cerebrospinal fluid rhinorrhea following transsphenoidal surgery. Acta Neurochir 147(11):1163-1166

37. Zanation AM, Carrau RL, Snyderman CH, Germanwala AV, Gardner PA, Prevedello DM et al (2009) Nasoseptal flap reconstruction of high flow intraoperative cerebral spinal fluid leaks during endoscopic skull base surgery. Am J Rhinol Allergy 23(5):518-521

38. Ogiwara T, Nagm A, Hasegawa T, Hanaoka Y, Ichinose S, Goto $\mathrm{T}$ et al (2019) Pitfalls of skull base reconstruction in endoscopic endonasal approach. Neurosurg Rev 42(3):683-689. https://doi. org/10.1007/s10143-018-1006-5

39. Cohen-Gadol AA, Bellew MP, Akard W, Payner TD (2010) The application of n-butyl 2-cyanoacrylate to repair CSF fistulas for 221 patients who underwent transsphenoidal surgery. Minim Invas Neurosurg 53(04):207-209

40. Conger A, Zhao F, Wang X, Eisenberg A, Griffiths C, Esposito $F$ et al (2018) Evolution of the graded repair of CSF leaks and skull base defects in endonasal endoscopic tumor surgery: trends in repair failure and meningitis rates in 509 patients. J Neurosurg 130(3):861-875

41. Zapata HDJ, Berrocal VR, Fernández CV, Sánchez FM, Fernández AG (2020) Sellar diaphragm reconstruction with tachosil during endoscopic endonasal surgery. J Neurol Surg B 81(03):275-279

42. Xue H, Wang X, Yang Z, Bi Z, Liu P (2020) Risk factors and outcomes of cerebrospinal fluid leak related to endoscopic pituitary adenoma surgery. Br J Neurosurg. https://doi.org/10.1080/02688 697.2020

43. Zhou Q, Yang Z, Wang X, Wang Z, Zhao C, Zhang S et al (2017) Risk factors and management of intraoperative cerebrospinal fluid leaks in endoscopic treatment of pituitary adenoma: analysis of 492 patients. World Neurosurg 101:390-395

44. Liu JK, Schmidt RF, Choudhry OJ, Shukla PA, Eloy JA (2012) Surgical nuances for nasoseptal flap reconstruction of cranial base defects with high-flow cerebrospinal fluid leaks after endoscopic skull base surgery. Neurosurg Focus 32(6):E7

45. Kuan EC, Yoo F, Patel PB, Su BM, Bergsneider M, Wang MB (2018) An algorithm for sellar reconstruction following the endoscopic endonasal approach: a review of 300 consecutive cases. J Neurol Surg B 79(2):177-183. https://doi.org/10.1055/s-00371606293

46. Mortuaire G, Vandeville S, Assaker R, Chevalier D (2012) Endoscopic repair of anterior or middle skull base cerebrospinal fluid leaks after tumour resection. Eur Ann Otorhinolaryngol Head Neck Dis 129(2):77-81

47. Nix P, Tyagi A, Phillips N (2016) Retrospective analysis of anterior skull base CSF leaks and endoscopic repairs at leeds. $\mathrm{Br}$ J Neurosurg 30(4):422-426. https://doi.org/10.3109/02688697. 2016.1161176

48. Gruss CL, Al Komser M, Aghi MK, Pletcher SD, Goldberg AN, McDermott M et al (2014) Risk factors for cerebrospinal leak after endoscopic skull base reconstruction with nasoseptal flap. Otolaryngol-Head Neck Surg 151(3):516-521

49. Liu B, Wang Y, Zheng T, Liu S, Lv W, Lu D et al (2020) Effect of intraoperative lumbar drainage on gross total resection and cerebrospinal fluid leak rates in endoscopic transsphenoidal surgery of pituitary macroadenomas. World Neurosurg 135:e629-e639

50. Cavallo LM, Solari D, Somma T, Cappabianca P (2019) The 3F (Fat, Flap, and Flash) technique for skull base reconstruction after endoscopic endonasal suprasellar approach. World Neurosurg 126:439-446. https://doi.org/10.1016/j.wneu.2019.03.125

51. Bergsneider M, Xue K, Suh JD, Wang MB (2012) Barrier-limited multimodality closure for reconstruction of wide sellar openings. Oper Neurosurg 71(suppl_1):ons58-ons76

52. Hadad G, Bassagasteguy L, Carrau RL, Mataza JC, Kassam A, Snyderman $\mathrm{CH}$ et al (2006) A novel reconstructive technique after endoscopic expanded endonasal approaches: vascular pedicle nasoseptal flap. Laryngoscope 116(10):1882-1886

53. Iannelli A, Lenzi R, Muscatello L (2014) A useful maneuver to simplify sellar floor repair following endoscopic transnasal pituitary surgery. J Neurol Surg A 75(02):158-160

54. Sade B, Mohr G, Frenkiel S (2006) Management of intra-operative cerebrospinal fluid leak in transnasal transsphenoidal pituitary microsurgery: use of post-operative lumbar drain and sellar reconstruction without fat packing. Acta Neurochir 148(1):13-19

55. Trinh VT, Duckworth EAM (2015) Scarless abdominal fat graft harvest for neurosurgical procedures. J Neurol Surg B 76(1):25

56. Roca E, Penn DL, Safain MG, Burke WT, Castlen JP, Laws ER (2019) Abdominal fat graft for sellar reconstruction: retrospective outcomes review and technical note. Oper Neurosurg 16(6):667-674. https://doi.org/10.1093/ons/opy219

57. Wessell A, Singh A, Litvack Z (2013) One-piece modified gasket seal technique. J Neurol Surg B 74(5):305

58. Xue H, Yang Z, Liu J, Wang X, Bi Z, Liu P (2019) Continuous dural suturing for closure of grade 3 leaks after tumor removal via an endoscopic endonasal approach. Neurosurg Rev. https:// doi.org/10.1007/s10143-019-01199-w

59. Iacoangeli M, Di Rienzo A, di Somma LGM, Moriconi E, Alvaro $\mathrm{L}, \mathrm{Re} \mathrm{M}$ et al (2014) Improving the endoscopic endonasal transclival approach: the importance of a precise layer by layer reconstruction. Br J Neurosurg 28(2):241-246

60. Rabadán AT, Hernández D, Ruggeri CS (2009) Pituitary tumors: our experience in the prevention of postoperative cerebrospinal fluid leaks after transsphenoidal surgery. J Neurooncol 93(1):127-131. https://doi.org/10.1007/s11060-009-9858-8 
61. Campos F, Fujio S, Sugata S, Tokimura H, Hanaya R, Bohara $M$ et al (2013) Effect of thrombin concentration on the adhesion strength and clinical application of fibrin glue-soaked sponge. Neurol Med Chir 53(1):17-20

62. Gaynor BG, Benveniste RJ, Lieberman S, Casiano R, Morcos JJ (2013) Acellular dermal allograft for sellar repair after transsphenoidal approach to pituitary adenomas. J Neurol Surg B 74(3): 155

63. Ismail M, Abd Alla Fares BA, D'Haens J, Michel O (2016) Sellar reconstruction without intrasellar packing after endoscopic surgery of pituitary macroadenomas is better than its reputation. GMS German Med Sci. https://doi.org/10.3205/000234

64. Ishii Y, Tahara S, Hattori Y, Teramoto A, Morita A, Matsuno A (2015) Fascia patchwork closure for endoscopic endonasal skull base surgery. Neurosurg Rev 38(3):551-557

65. Ahn JY, Kim SH (2009) A new technique for dural suturing with fascia graft for cerebrospinal fluid leakage in transsphenoidal surgery. Oper Neurosurg 65(suppl_6):ons65-ons72

66. Ishii Y, Tahara S, Teramoto A, Morita A (2014) Endoscopic endonasal skull base surgery: advantages, limitations, and our techniques to overcome cerebrospinal fluid leakage. Neurol Med Chir. https://doi.org/10.2176/nmc.st.2014-0081

67. Ishikawa T, Takeuchi K, Nagata Y, Choo J, Kawabata T, Ishizaki T et al (2018) Three types of dural suturing for closure of CSF leak after endoscopic transsphenoidal surgery. J Neurosurg. https://doi.org/10.3171/2018.4.Jns18366

68. Hara T, Akutsu H, Yamamoto T, Tanaka S, Takano S, Ishikawa E et al (2015) Cranial base repair using suturing technique combined with a mucosal flap for cerebrospinal fluid leakage during endoscopic endonasal surgery. World Neurosurg 84(6): 1887-1893

69. Nishioka H, Izawa H, Ikeda Y, Namatame H, Fukami S, Haraoka J (2009) Dural suturing for repair of cerebrospinal fluid leak in transnasal transsphenoidal surgery. Acta Neurochir 151(11):1427

70. Kitano M, Taneda M (2007) Icing and multilayering technique of injectable hydroxyapatite cement paste for cranial base reconstruction after transsphenoidal surgery. Oper Neurosurg 61(suppl_3):ONS-E53

71. Moon JH, Kim EH, Kim SH (2016) Snare technique for the remodeling of the redundant arachnoid pouch to prevent cerebrospinal fluid rhinorrhea and hematoma collection during transsphenoidal surgery for suprasellar-extended pituitary tumors. J Neurosurg 125(6):1443-1450. https://doi.org/10.3171/2015.11. Jns 151328

72. Kim EH, Moon JH, Kim SH (2019) Clipping technique for the repair of the intraoperative cerebrospinal fluid leakage during transsphenoidal pituitary tumor surgery. Oper Neurosurg 17(4):382-388. https://doi.org/10.1093/ons/opy408

73. Kobayashi H, Asaoka K, Terasaka S, Murata J-I (2011) Primary closure of a cerebrospinal fluid fistula by nonpenetrating titanium clips in endoscopic endonasal transsphenoidal surgery. Skull Base 21(1):47

74. Peizhi Z, Jianjian T, Ji Z, Youping L, Shu J (2012) A new technique for clipping diaphragm defects in transsphenoidal surgery. Turk Neurosurg 22(3):336-340

75. Kassam AB, Thomas A, Carrau RL, Snyderman CH, Vescan A, Prevedello D et al (2008) Endoscopic reconstruction of the cranial base using a pedicled nasoseptal flap. Oper Neurosurg 63(suppl_1):ONS44-ONS53

76. Burkett CJ, Patel S, Tabor MH, Padhya T, Vale FL (2011) Polyethylene glycol (PEG) hydrogel dural sealant and collagen dural graft matrix in transsphenoidal pituitary surgery for prevention of postoperative cerebrospinal fluid leaks. J Clin Neurosci 18(11):1513-1517

77. Cappabianca P, Esposito F, Cavallo LM, Messina A, Solari D, di Somma LGM et al (2006) Use of equine collagen foil as dura mater substitute in endoscopic endonasal transsphenoidal surgery. Surg Neurol 65(2):144-148

78. Zenga F, Tardivo V, Pacca P, Garzaro M, Garbossa D, Ducati A (2016) Nanofibrous synthetic dural patch for skull base defects: preliminary experience for reconstruction after extended endonasal approaches. J Neurol Surg Rep 77(1):e50

79. Locatelli D, Vitali M, Custodi VM, Scagnelli P, Castelnuovo P, Canevari FR (2009) Endonasal approaches to the sellar and parasellar regions: closure techniques using biomaterials. Acta Neurochir 151(11):1431

80. El-Banhawy OA, Halaka AN, Altuwaijri MA, Ayad H, El-Sharnoby MM (2008) Long-term outcome of endonasal endoscopic skull base reconstruction with nasal turbinate graft. Skull Base 18(5):297

81. Amano K, Hori T, Kawamata T, Okada Y (2016) Repair and prevention of cerebrospinal fluid leakage in transsphenoidal surgery: a sphenoid sinus mucosa technique. Neurosurg Rev 39(1):123-131

82. Fishpool SJC, Amato-Watkins A, Hayhurst C (2017) Free middle turbinate mucosal graft reconstruction after primary endoscopic endonasal pituitary surgery. Eur Arch Otorhinolaryngol 274(2):837-844

83. Scagnelli RJ, Patel V, Peris-Celda M, Kenning TJ, Pinheiro-Neto CD (2019) Implementation of free mucosal graft technique for sellar reconstruction after pituitary surgery: outcomes of 158 consecutive patients. World Neurosurg 122:e506-e511. https:// doi.org/10.1016/j.wneu.2018.10.090

84. Soldatova L, Campbell RG, Elkhatib AH, Schmidt TW, Pinto NR, Pinto JM et al (2017) Role of leukocyte-platelet-rich fibrin in endoscopic endonasal skull base surgery defect reconstruction. J Neurol Surg B 78(1):59

85. Theys T, Van Hoylandt A, Broeckx CE, Van Gerven L, Jonkergouw J, Quirynen M et al (2018) Plasma-rich fibrin in neurosurgery: a feasibility study. Acta Neurochir 160(8):1497-1503. https://doi.org/10.1007/s00701-018-3579-8

86. Rasmussen J, Ruggeri C, Ciraolo C, Baccanelli M, Yampolsky C, Ajler P (2018) Application of fibrin rich in leukocytes and platelets in the reconstruction of endoscopic approaches to the skull base. World Neurosurg 118:32-41. https://doi.org/10.1016/j. wneu.2018.06.180

87. Berker M, Aghayev K, Yücel T, Hazer DB, Onerci M (2013) Management of cerebrospinal fluid leak during endoscopic pituitary surgery. Auris Nasus Larynx 40(4):373-378. https://doi.org/ 10.1016/j.anl.2012.11.006

88. Cho JM, Ahn JY, Chang JH, Kim SH (2011) Prevention of cerebrospinal fluid rhinorrhea after transsphenoidal surgery by collagen fleece coated with fibrin sealant without autologous tissue graft or postoperative lumbar drainage. Oper Neurosurg 68(suppl_1):ons130-ons137

89. Malik MU, Aberle JC, Flitsch J (2012) CSF fistulas after transsphenoidal pituitary surgery: a solved problem? J Neurol Surg A 73(05):275-280

90. Citardi MJ, Cox Iii AJ, Bucholz RD (2000) Acellular dermal allograft for sellar reconstruction after transsphenoidal hypophysectomy. Am J Rhinol 14(1):69-74

91. Eichberg DG, Richardson AM, Brusko GD, Ali SC, Buttrick SS, Shah AH et al (2019) The use of dehydrated amniotic membrane allograft for augmentation of dural repair in transsphenoidal endoscopic endonasal resection of pituitary adenomas. Acta Neurochir 161(10):2117-2122

92. Youngerman BE, Kosty JA, Gerges MM, Tabaee A, Kacker A, Anand VK et al (2020) Acellular dermal matrix as an alternative to autologous fascia lata for skull base repair following extended endoscopic endonasal approaches. Acta Neurochir 162(4):863-873 
93. Cavallo LM, Solari D, Somma T, Di Somma A, Chiaramonte C, Cappabianca P (2013) Use of equine pericardium sheet (LYOMESH( $\left.{ }^{(}\right)$as dura mater substitute in endoscopic endonasal transsphenoidal surgery. Transl Med 7:23

94. Luginbuhl AJ, Campbell PG, Evans J, Rosen M (2010) Endoscopic repair of high-flow cranial base defects using a bilayer button. Laryngoscope 120(5):876-880

95. Cappabianca P, Esposito F, Magro F, Cavallo LM, Solari D, Stella L et al (2010) Natura abhorret a vacuo: use of fibrin glue as a filler and sealant in neurosurgical "dead spaces". Technical note. Acta Neurochir 152(5):897-904

96. Kumar A, Maartens NF, Kaye AH (2003) Reconstruction of the sellar floor using Bioglue following transsphenoidal procedures. J Clin Neurosci 10(1):92-95

97. Schuss P, Hadjiathanasiou A, Klingmüller D, Güresir Á, Vatter H, Güresir E (2018) Transsphenoidal pituitary surgery: comparison of two sellar reconstruction techniques and their effect on postoperative cerebrospinal fluid leakage. Neurosurg Rev 41(4):1053-1058. https://doi.org/10.1007/s10143-018-0949-x

98. Yildirim AE, Dursun E, Ozdol C, Divanlioglu D, Nacar OA, Koyun OK et al (2013) Using an autologous fibrin sealant in the preventing of cerebrospinal fluid leak with large skull base defect following endoscopic endonasal transsphenoidal surgery. Turk Neurosurg 23(6):736-741

99. Nakayama N, Yano H, Egashira Y, Enomoto Y, Ohe N, Kanemura $\mathrm{N}$ et al (2018) Efficacy, reliability, and safety of completely autologous fibrin glue in neurosurgical procedures: singlecenter retrospective large-number case study. World Neurosurg 109:e819-e828

100. Pereira EAC, Grandidge CA, Nowak VA, Cudlip SA (2017) Cerebrospinal fluid leaks after transsphenoidal surgery: effect of a polyethylene glycol hydrogel dural sealant. J Clin Neurosci 44:6-10

101. Eloy JA, Choudhry OJ, Shukla PA, Kuperan AB, Friedel ME, Liu JK (2012) Nasoseptal flap repair after endoscopic transsellar versus expanded endonasal approaches: is there an increased risk of postoperative cerebrospinal fluid leak? Laryngoscope 122(6):1219-1225

102. Couldwell WT, Kan P, Weiss MH (2006) Simple closure following transsphenoidal surgery. Neurosurg Focus 20(3):1-3

103. Sanders-Taylor C, Anaizi A, Kosty J, Zimmer LA, Theodosopoulos PV (2015) Sellar reconstruction and rates of delayed cerebrospinal fluid leak after endoscopic pituitary surgery. J Neurol Surg B 76(4):281

104. Seda L, Camara RB, Cukiert A, Burattini JA, Mariani PP (2006) Sellar floor reconstruction after transsphenoidal surgery using fibrin glue without grafting or implants. Surg Neurol 66(1):46-49

105. Jin B, Wang X-s, Huo G, Mou J-m, Yang G (2020) Reconstruction of skull base bone defects using an in situ bone flap after endoscopic endonasal transplanum-transtuberculum approaches. Eur Arch Otorhinolaryngol. https://doi.org/10.1007/ s00405-020-05911-1

106. Kim S, Jeon C, Kong D-S, Park K, Kim JH (2011) Clinical efficacy of radiation-sterilized allografts for sellar reconstruction after transsphenoidal surgery. J Korean Neurosurg Soc 50(6):503

107. Chung S-B, Nam D-H, Park K, Kim JH, Kong D-S (2012) Injectable hydroxyapatite cement patch as an on-lay graft for the sellar reconstructions following endoscopic endonasal approach. Acta Neurochir 154(4):659-664

108. Moliterno JA, Mubita LL, Huang C, Boockvar JA (2010) Highviscosity polymethylmethacrylate cement for endoscopic anterior cranial base reconstruction. J Neurosurg 113(5):1100-1105

109. Leng LZ, Brown S, Anand VK, Schwartz TH (2008) "Gasketseal" watertight closure in minimal-access endoscopic cranial base surgery. Operat Neurosurg 62(suppl_5):ONS342-ONS343
110. Kong D-S, Kim HY, Kim S-H, Min J-Y, Nam D-H, Park K et al (2011) Challenging reconstructive techniques for skull base defect following endoscopic endonasal approaches. Acta Neurochir 153(4):807-813

111. Hong CK, Kim YB, Hong JB, Lee KS (2015) Sealing of cerebrospinal fluid leakage during conventional transsphenoidal surgery using a fibrin-coated collagen fleece. J Clin Neurosci 22(4):696-699

112. Garcia-Navarro V, Anand VK, Schwartz TH (2013) Gasket seal closure for extended endonasal endoscopic skull base surgery: efficacy in a large case series. World Neurosurg 80(5):563-568

113. Xuejian W, Fan H, Xiaobiao Z, Yong Y, Ye G, Tao X et al (2013) Endonasal endoscopic skull base multilayer reconstruction surgery with nasal pedicled mucosal flap to manage high flow CSF leakage. Turk Neurosurg 23(4):439-445. https://doi.org/10.5137/ 1019-5149.Jtn.6176-12.0

114. Eloy JA, Patel AA, Shukla PA, Choudhry OJ, Liu JK (2013) Early harvesting of the vascularized pedicled nasoseptal flap during endoscopic skull base surgery. Am J Otolaryngol 34(3):188-194

115. Hu F, Gu Y, Zhang X, Xie T, Yu Y, Sun C et al (2015) Combined use of a gasket seal closure and a vascularized pedicle nasoseptal flap multilayered reconstruction technique for high-flow cerebrospinal fluid leaks after endonasal endoscopic skull base surgery. World Neurosurg 83(2):181-187

116. Shin J-H, Kang S-G, Kim SW, Hong YK, Jeun S-S, Kim EH et al (2013) Bilateral nasoseptal flaps for endoscopic endonasal transsphenoidal approach. J Craniofac Surg 24(5):1569-1572

117. Nyquist GG, Anand VK, Singh A, Schwartz TH (2010) Janus flap: bilateral nasoseptal flaps for anterior skull base reconstruction. Otolaryngol Head Neck Surg 142(3):327-331. https://doi. org/10.1016/j.otohns.2009.12.020

118. Horiguchi K, Nishioka H, Fukuhara N, Yamaguchi-Okada M, Yamada S (2016) A new multilayer reconstruction using nasal septal flap combined with fascia graft dural suturing for highflow cerebrospinal fluid leak after endoscopic endonasal surgery. Neurosurg Rev 39(3):419-427

119. Horiguchi K, Murai H, Hasegawa Y, Hanazawa T, Yamakami I, Saeki N (2010) Endoscopic endonasal skull base reconstruction using a nasal septal flap: surgical results and comparison with previous reconstructions. Neurosurg Rev 33(2):235-241

120. Patel MR, Taylor RJ, Hackman TG, Germanwala AV, SasakiAdams D, Ewend MG et al (2014) Beyond the nasoseptal flap: outcomes and pearls with secondary flaps in endoscopic endonasal skull base reconstruction. Laryngoscope 124(4):846-852

121. El-Sayed IH, Roediger FC, Goldberg AN, Parsa AT, McDermott MW (2008) Endoscopic reconstruction of skull base defects with the nasal septal flap. Skull Base 18(6):385

122. Tewfik MA, Valdes CJ, Zeitouni A, Sirhan D, Di Maio S (2014) The endoscopic hemi-transseptal approach to the sella turcica: operative technique and case-control study. J Neurol Surg B 75(6):415

123. Singh C, Shah N (2019) Posterior nasoseptal flap in the reconstruction of skull base defects following endonasal surgery. J Laryngol Otol 133(5):380-385. https://doi.org/10.1017/s0022 215119000926

124. Fnais N, Di Maio S, Edionwe S, Zeitouni A, Sirhan D, Valdes CJ et al (2017) Hemi-transseptal approach for pituitary surgery: a follow-up study. J Neurol Surg B 78(2):145

125. Rivera-Serrano CM, Snyderman CH, Gardner P, Prevedello D, Wheless S, Kassam AB et al (2011) Nasoseptal "rescue" flap: a novel modification of the nasoseptal flap technique for pituitary surgery. Laryngoscope 121(5):990-993. https://doi.org/10.1002/ lary. 21419

126. Otto BA, Bowe SN, Carrau RL, Prevedello DM, Ditzel Filho LF, de Lara D (2013) Transsphenoidal approach with nasoseptal flap 
pedicle transposition: modified rescue flap technique. Laryngoscope 123(12):2976-2979

127. Ozawa H, Tomita T, Watanabe Y, Sekimizu M, Ito F, Ikari Y et al (2016) Sigmoid incision rescue nasoseptal flap technique for endoscopic endonasal skull base surgery. Acta Otolaryngol 136(6):636-640

128. Gode S, Lieber S, Nakassa ACI, Wang EW, Fernandez-Miranda JC, Gardner PA et al (2019) Clinical experience with secondary endoscopic reconstruction of clival defects with extracranial pericranial flaps. J Neurol Surg B 80(3):276-282. https://doi.org/ 10.1055/s-0038-1668517

129. Thorp BD, Sreenath SB, Ebert CS, Zanation AM (2014) Endoscopic skull base reconstruction: a review and clinical case series of 152 vascularized flaps used for surgical skull base defects in the setting of intraoperative cerebrospinal fluid leak. Neurosurg Focus 37(4):E4

130. Amin SM, Fawzy TO, Hegazy AA (2016) Composite vascular pedicled middle turbinate flap for reconstruction of sellar defects. Ann Otol Rhinol Laryngol 125(9):770-774

131. Carnevale C, Tomás-Barberán M, Til-Pérez G, IbañezDomínguez J, Arancibia-Tagle D, Rodríguez-Villalba R et al (2019) Endoscopic reconstruction of large anterior skull base defects with opening of the sellar diaphragm. Experience at a tertiary level university hospital. J Laryngol Otol 133(10):889-894

132. Patel MR, Shah RN, Snyderman CH, Carrau RL, Germanwala AV, Kassam AB et al (2010) Pericranial flap for endoscopic anterior skull-base reconstruction: clinical outcomes and radioanatomic analysis of preoperative planning. Neurosurgery 66(3):506-512

133. Kang SY, Eskander A, Hachem RA, Ozer E, Teknos TN, Old MO et al (2018) Salvage skull base reconstruction in the endoscopic era: Vastus lateralis free tissue transfer. Head Neck 40(4):E45E52. https://doi.org/10.1002/hed.25094

134. Gode S, Lieber S, Nakassa ACI, Wang EW, Fernandez-Miranda JC, Gardner PA et al (2019) Clinical experience with secondary endoscopic reconstruction of clival defects with extracranial pericranial flaps. J Neurol Surg B 80(03):276-282

135. Lavigne P, Vega MB, Ahmed OH, Gardner PA, Snyderman CH, Wang EW (2020) Lateral nasal wall flap for endoscopic reconstruction of the skull base: anatomical study and clinical series. Int Forum Allergy Rhinol 10:673-678

136. Cong Z, Liu K, Wen G, Qiao L, Wang H, Ma C (2018) Universal sellar anatomical reconstruction using the sellar floor flap after endoscopic pituitary adenoma surgery. Otolaryngol Head Neck Surg 158(4):774-776. https://doi.org/10.1177/0194599818 756861

137. Farrell NF, Kingdom TT, Getz AE, Lillehei KO, Youssef AS, Ramakrishnan VR (2019) Development of chronic sphenoid sinusitis after sellar reconstruction with medpor porous polyethylene implant. World Neurosurg 123:e781-e786

138. Kim J, Cheong J, Yi H, Bak K, Kim C, Lee S (2002) Usefulness of silicone plate for sellar floor reconstruction. Minim Invas Neurosurg 45(02):124-127

139. Liebelt BD, Huang M, Baskin DS (2015) Sellar floor reconstruction with the Medpor implant versus autologous bone after transnasal transsphenoidal surgery: outcome in 200 consecutive patients. World Neurosurg 84(2):240-245

140. Zeden J-P, Baldauf J, Schroeder HWS (2020) Repair of the sellar floor using bioresorbable polydioxanone foils after endoscopic endonasal pituitary surgery. Neurosurg Focus 48(6):E16
141. Massoud EAS, Hebb ALO, Clarke DB (2020) Securing the position of the nasoseptal flap in endoscopic transsphenoidal surgery: no need for a Foley catheter (technical report). Am J Otolaryngol 41:102417

142. Liu JK, Mendelson ZS, Kohli G, Eloy JA (2018) Relaxing sphenoidal slit incision to extend the anterior and posterior reach of pedicled nasoseptal flaps during endoscopic skull base reconstruction of transcribriform defects: technical note and results in 20 patients. World Neurosurg 113:49-57. https://doi.org/10. 1016/j.wneu.2018.01.142

143. Dehdashti AR, Stofko D, Okun J, Obourn C, Kennedy T (2016) Endoscopic endonasal reconstruction of skull base: repair protocol. J Neurol Surg B 77(3):271

144. Jakimovski D, Bonci G, Attia M, Shao H, Hofstetter C, Tsiouris $\mathrm{AJ}$ et al (2014) Incidence and significance of intraoperative cerebrospinal fluid leak in endoscopic pituitary surgery using intrathecal fluorescein. World Neurosurg 82(3-4):e513-e523

145. Banu MA, Kim J-H, Shin BJ, Woodworth GF, Anand VK, Schwartz TH (2014) Low-dose intrathecal fluorescein and etiology-based graft choice in endoscopic endonasal closure of CSF leaks. Clin Neurol Neurosurg 116:28-34

146. Zhan R, Chen S, Xu S, Liu JK, Li X (2015) Postoperative lowflow cerebrospinal fluid leak of endoscopic endonasal transsphenoidal surgery for pituitary adenoma: wait and see, or lumbar drain? J Craniofac Surg 26(4):1261

147. Caggiano C, Penn DL, Laws ER Jr (2018) The role of the lumbar drain in endoscopic endonasal skull base surgery: a retrospective analysis of 811 cases. World Neurosurg 117:e575-e579. https:// doi.org/10.1016/j.wneu.2018.06.090

148. Jonathan GE, Sarkar S, Singh G, Mani S, Thomas R, Chacko AG (2018) A randomized controlled trial to determine the role of intraoperative lumbar cerebrospinal fluid drainage in patients undergoing endoscopic transsphenoidal surgery for pituitary adenomas. Neurol India 66(1):133-138. https://doi.org/10.4103/ 0028-3886.222823

149. Zamanipoor Najafabadi AH, Khan DZ, Muskens IS, Broekman MLD, Dorward NL, van Furth WR et al (2020) Trends in cerebrospinal fluid leak rates following the extended endoscopic endonasal approach for anterior skull base meningioma: a metaanalysis over the last 20 years. Acta Neurochir. https://doi.org/ 10.1007/s00701-020-04641-x

150. Khan DZBS, Patel V, Schroeder BE, Cabrilo I, Choi D, Cudlip SA, Donnelly N, Dorward N, Fountain DM, Grieve J, Halliday J, Kolias AG, Mannion RJ, O'Donnell A, Phillips N, Piper RJ, Ramachandran B, Santarius T, Sayal P, Sharma R, Solomou G, Tysome JR, Marcus HJ, Neurology and Neurosurgery Interest Group, British Neurosurgical Trainee Research Collaborative, CRANIAL Steering Committee (2020) CSF rhinorrhoea after endonasal intervention to the anterior skull base (CRANIAL): proposal for a prospective multicentre observational cohort study. Br J Neurosurg. https://doi.org/10.1080/02688697.2020.179562

Publisher's Note Springer Nature remains neutral with regard to jurisdictional claims in published maps and institutional affiliations. 